\title{
In Vitro Effect of Dexamethasone, Pentoxifylline, and Anti-Endotoxin Monoclonal Antibody on the Release of Proinflammatory Mediators by Human Leukocytes Stimulated with Haemophilus influenzae Type B
}

\author{
A. MARCELINE van FURTH, THEA M. STEENWIJK, JAN A. M. LANGERMANS, AND \\ RALPH VAN FURTH
}

Department of Infectious Diseases, University Hospital, Leiden, The Netherlands [A.M.V.F., T.M.S., J.A.M.L., R.v.F.], and Department of Pediatrics, Juliana Childrens Hospital, The Hague, The Netherlands [A.M.v.F.]

\begin{abstract}
The effects of dexamethasone, pentoxifylline, and MAb against endotoxin (HA-1A) on the release of various proinflammatory mediators, i.e. tumor necrosis factor- $\alpha$ (TNF), IL-1 $\beta$, IL-8, and prostaglandin 2 , by human leukocytes during stimulation with Haemophilus influenzae type B were studied. The results show that only monocytes, and thus neither lymphocytes nor granulocytes, release these mediators in response to $H$. influenzae. Dexamethasone inhibited the release of all of these mediators, whereas pentoxifylline only inhibited the release of TNF. HA-1A only reduced the release of IL-8 from adherent monocytes significantly and had no significant effect on the release of TNF, IL-1 $\beta$, and prostaglandin $\mathbf{E}_{2}$. In whole blood, no significant effect of $\mathrm{HA}-1 \mathrm{~A}$ on the release of TNF, IL-1 $\beta$, IL-8, and prostaglandin $E_{2}$ was found. In summary, the results of this study demonstrate that dexamethasone is the most potent inhibitor of the release of proinflammatory mediators by monocytes induced by $\boldsymbol{H}$. influenzae type B. (Pediatr Res 35: 725-728, 1994)
\end{abstract}

Abbreviations

DXM, dexamethasone

PTX, pentoxifylline

TNF, tumor necrosis factor- $\alpha$

$\mathrm{PGE}_{2}$, prostaglandin $\mathrm{E}_{2}$

CSF, cerebrospinal fluid

LPS, lipopolysaccharide

\begin{abstract}
Despite early and adequate antibiotic treatment, mortality due to bacterial meningitis remains high, particularly among very young and elderly patients. For children up to $3 \mathrm{y}$ of age, Haemophilus influenzae type B is the most common cause of bacterial meningitis (1). The polysaccharide capsule of $H$. influenzae plays an important role in their invasion, whereas endotoxin is important in the genesis of blood-brain barrier injury through stimulation of the production of proinflammatory products, such as TNF, and eicosanoids, such as $\mathrm{PGE}_{2}$. These products increase the permeability of the blood-brain barrier, thus promoting enhanced migration of granulocytes and monocytes as well as leakage of plasma into the CSF, resulting in an

Received August 5, 1993; accepted January 31, 1994

Correspondence: Dr. R van Furth, Department of Infectious Diseases, University Hospital, Bldg. 1 C5-P, P.O. Box 9600, 2300 RC Leiden, The Netherlands.
\end{abstract}

inflammatory exudate, cerebral edema, increased intracranial pressure, and alteration of cerebral blood flow $(2,3)$. TNF and IL-1 have been demonstrated in the CSF of neonates and children with bacterial meningitis (4). High levels of IL-1 in the CSF of these patients correlate with the development of neurologic complications $(5,6)$. IL-8 enhances chemotaxis, attachment to endothelial cells, and diapedesis of leukocytes (7).

Release of bacterial surface structures due to treatment with antibiotics is probably responsible for the high morbidity and mortality during bacterial meningitis $(8,9)$.

To improve treatment of bacterial meningitis, many experimental and clinical studies have focused on adjunctive therapy with glucocorticosteroids, PTX, and MAb against endotoxin to limit inflammation and sequelae (10-14). Some of these compounds might be effective on the release of proinflammatory mediators. The aim of the present study was to compare the effects of DXM, PTX, and MAb against endotoxin on the release of proinflammatory mediators and $\mathrm{PGE}_{2}$ by human leukocytes during stimulation with $H$. influenzae in vitro.

\section{MATERIALS AND METHODS}

Microorganisms. H. influenzae (strain 760705) (a generous gift from Dr. L. van Alphen, Academic Medical Center, Amsterdam, The Netherlands) was cultured for $18 \mathrm{~h}$ at $37^{\circ} \mathrm{C}$ in Müller-Hinton broth containing $4 \%$ factor $\mathrm{V}$ and $0.08 \%$ factor $\mathrm{X}$. The bacteria were collected by centrifugation $(10 \mathrm{~min} ; 1500 \times \mathrm{g})$, washed twice with PBS ( $\mathrm{pH} 7.4$ ), and suspended at appropriate bacterial concentrations in PBS. Bacteria were killed by incubation at $70^{\circ} \mathrm{C}$ for $1 \mathrm{~h}$. After centrifugation of $5 \times 10^{6}$ heat-killed bacteria $(10 \mathrm{~min} ; 1500 \times \mathrm{g})$ and filtration through a Millipore filter (4 $\mu \mathrm{M}$, Millipore, Costar, Cambridge, MA), the cell-free supernatant contained $16 \mu \mathrm{g} / \mathrm{L}$ free LPS.

Isolation of Monocytes. Monocytes were isolated from the buffy coats of blood from healthy donors by differential centrifugation on Ficoll-Hypaque gradients $(\rho=1.077 \mathrm{~kg} / \mathrm{L}$, Pharmacia, Upsala, Sweden). The interphase with mononuclear cells was washed with PBS containing $5 \times 10^{2} \mathrm{U} / \mathrm{L}$ heparin and suspended in medium to a concentration of $3-4 \times 10^{10}$ cells per $\mathrm{L}$. This suspension contained $30-35 \%$ monocytes and less than $2 \%$ granulocytes. Cell viability exceeded $98 \%$, as determined by trypan blue exclusion. All experiments were performed in siliconized glassware to prevent adherence of the monocytes to the glass surface.

Monocytes were purified from the Ficoll-Hypaque interphase by adherence or elutriation.

Isolation of monocytes by adherence. One $\mathrm{mL}$ of a cell suspen- 
sion containing $1 \times 10^{9}$ monocytes/L medium was cultured in the plastic wells of a 24-well tissue culture plate (Costar, Cambridge, UK). Two h later, nonadherent cells were removed by washing once with PBS; $1 \mathrm{~mL}$ of RPMI 1640 (Flow Laboratories, Rockville, MD) containing 10\% heat-inactivated FCS (Flow Laboratories, Irvine, Scotland), $1 \times 10^{5} \mathrm{U} / \mathrm{L}$ penicillin, and 50 $\mathrm{mg} / \mathrm{L}$ streptomycin (referred to as medium from here on) was then added. The adherent cell population consisted of $93 \% \pm 2$ of monocytes.

Isolation of monocytes by elutriation. Monocytes were purified from the Ficoll-Hypaque interphase by countercurrent centrifugal elutriation in a Beckmann J2-21 M/E centrifuge using a JE6 elutriation rotor (Beckmann Instruments, Palo Alto, CA). The suspension contained $80-90 \%$ pure monocytes.

All materials contained less than 20 pg LPS, as determined by the Limulus lysate assay.

Isolation of Granulocytes and Lymphocytes. Granulocyte suspensions were isolated from the Ficoll-Hypaque pellets from which erythrocytes had been removed by sedimentation with Plasmasterile (Fresenius AG, Bad Homburg, Germany) for 10 min at $1 \times g$ at $37^{\circ} \mathrm{C}$. Residual erythrocytes were lysed once with distilled water for $30 \mathrm{~s}$ at $4^{\circ} \mathrm{C}$, and the remaining granulocytes were washed with PBS and resuspended in medium. These cell preparations contained virtually no erythrocytes and yielded at least $98 \%$ granulocytes with less than $2 \%$ monocyte contamination. Lymphocytes were purified from the Ficoll-Hypaque interphase by countercurrent centrifugal elutriation in a Beckmann J2-21 M/E centrifuge using a JE-6 elutriation rotor. The suspensions yielded greater than $80 \%$ lymphocytes with less than $9 \%$ monocyte contamination. Granulocytes and lymphocytes were more than $95 \%$ viable, as assessed by trypan blue exclusion.

Stimulation of Release of Mediators. Fresh heparinized $\left(10^{4}\right.$ $\mathrm{U} / \mathrm{L}$ ) blood from healthy volunteers was diluted 5-fold with RPMI containing $10^{5} \mathrm{U} / \mathrm{L}$ penicillin and $50 \mathrm{mg} / \mathrm{L}$ streptomycin. One-mL aliquots of blood were incubated with $5 \times 10^{6}$ heatkilled $H$. influenzae in 24-well tissue culture plates for $18 \mathrm{~h}$ at $37^{\circ} \mathrm{C}$ at $7.5 \% \mathrm{CO}_{2}$; the suspension was then centrifuged $(10 \mathrm{~min}$; $1500 \times \mathrm{g}$ ); the resulting supernatant was collected, filtered (Millipore, Costar) and used to quantify the mediators under study. The same experiment was performed with monocytes, isolated by adherence or elutriation, elutriated lymphocytes, and granulocytes; a concentration of $5 \times 10^{9}$ cells/ $\mathrm{L}$ was incubated with 1 $\times 10^{9} / \mathrm{L}$ heat-killed $H$. influenzae in $1 \mathrm{~mL}$ of medium for $18 \mathrm{~h}$. For description of experimental conditions and collection and assessment of the supernatant, see above.

Measurement of Proinflammatory Mediators. The concentrations of TNF, IL- $1 \beta$, and IL-8 in plasma or supernatant were measured by means of ELISA according to instructions from the manufacturer (Amersham, Bucks, UK). After removal of proteins from the plasma or supernatant by ethanol extraction, $\mathrm{PGE}_{2}$ was extracted by means of a $\mathrm{C} 18$ octadecyl column (Amersham) and assessed by RIA (Amersham).

Inhibition of Release of Mediators. Various concentrations of DXM (MSD, Haarlem, The Netherlands), PTX (Hoechst AG, Wiesbaden, Germany), and anti-endotoxin MAb (HA-1 A) (Centocor, Leiden, The Netherlands) were used for the incubation of blood as well as the suspension of isolated leukocytes and adherent monocytes. The amount of proinflammatory mediators was then measured as described above.

Binding of $H A-I A$ to $H$. influenzae. Binding of HA-1A to $H$. influenzae was measured by ELISA. In short, microwells (Nunclon plates, Intermed, Roskilde, Danmark) were coated by overnight incubation with $1 \times 10^{7}$ heat-killed $H$. influenzae in carbonate buffer ( $\mathrm{pH} 9.6)$ at room temperature. After washing with PBS containing $0.05 \%$ Tween-20 (PBS-Tween), nonspecific binding sites were blocked by incubating the wells for $30 \mathrm{~min}$ with $100 \mu \mathrm{L}$ of $10 \%$ heat-inactivated newborn calf serum in PBSTween at room temperature. Next, wells were incubated for 60 min with $100 \mu \mathrm{L}$ of HA-1A in PBS-Tween in serial dilutions from $100 \mu \mathrm{g}$ to $1000 \mu \mathrm{g} / \mathrm{L}$, then washed and incubated with an optimal dilution of $100 \mu \mathrm{L}$ of goat-anti-human IgM conjugated to horseradish peroxidase (Nordic, Tilburg, The Netherlands). Tetramethylbenzidine was used as a substrate for the horseradish peroxidase, and absorption was measured at $450 \mathrm{~nm}$. As a control, wells were incubated with human IgM instead of HA$1 \mathrm{~A}$.

Statistical Analysis. The results are expressed as medians and $95 \%$ intervals of at least four to seven experiments unless otherwise stated. The significance of the differences between values was determined by the Mann-Whitney $U$ test. The level of significance was set at 0.05 .

\section{RESULTS}

Release of various proinflammatory mediators by leukocytes in whole blood stimulated by $H$. influenzae. Incubation of whole blood with heat-killed $H$. influenzae resulted in the time-dependent release of various proinflammatory mediators into the culture supernatant (Fig. 1). TNF was already detectable after $3 \mathrm{~h}$ of incubation. Peak levels were reached at $6 \mathrm{~h}$; the concentration of TNF subsequently decreased. After $3 \mathrm{~h}$ of incubation, IL- $1 \beta$ was not detectable; concentrations were maximal at $6 \mathrm{~h}$ and remained high for $18 \mathrm{~h}$. Increasing levels of IL-8 and PGE $\mathrm{PG}_{2}$ were found during the 24-h incubation period; therefore, in subsequent experiments the concentrations of the proinflammatory mediators were determined at $18 \mathrm{~h}$.

Effect of DXM on release of proinflammatory mediators. After $18 \mathrm{~h}$ of stimulation of leukocytes in whole blood with heat-killed $H$. influenzae, high concentrations of the proinflammatory mediators TNF, IL-1 $\beta$, IL-8, and $\mathrm{PGE}_{2}$ were present. When $0.5 \mathrm{mg} /$ $\mathrm{L}$ or $0.1 \mathrm{mg} / \mathrm{L} \mathrm{DXM}$ was added, there was a significant $(p<$ $0.05)$ decrease in the release of these proinflammatory mediators. The percentages of decrease at $18 \mathrm{~h}$ were $96 \pm 3 \%$ for TNF, 73 $\pm 24 \%$ for IL-1 $\beta, 75 \pm 15 \%$ for IL-8, and $96 \pm 5 \%$ for $\mathrm{PGE}_{2}$ (Fig. 2). A similar decrease in cytokine release was found when adherent monocytes were stimulated with $H$. influenzae in the presence of DXM, i.e. a $72 \pm 14 \%$ decrease in TNF, a $63 \pm 22 \%$ decrease in IL-8, and a $77 \pm 13 \%$ decrease in $\mathrm{PGE}_{2}$; in contrast, IL- $1 \beta$ exhibited a decrease of only $24 \pm 22 \%$, which was not significant (Fig. 2).

Effect of PTX on release of proinflammatory mediators. Whole blood incubated with heat-killed $H$. influenzae and $100 \mathrm{mg} / \mathrm{L}$ PTX resulted in a significant $(p<0.05)$ decrease of $91 \pm 3 \%$ in

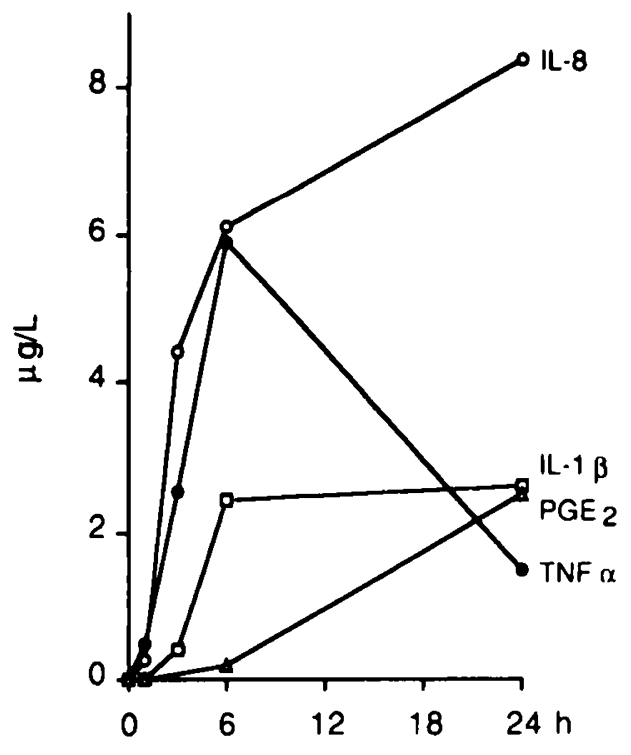

Fig. 1. Course of the release of TNF, IL-1 $\beta$, IL-8, and $\mathrm{PGE}_{2}$ by leukocytes in whole blood stimulated with $5 \times 10^{6}$ heat-killed $H$. influenzae. At several time points, samples were taken for determination of the concentration of the various mediators. The values represent the mean of three experiments. 

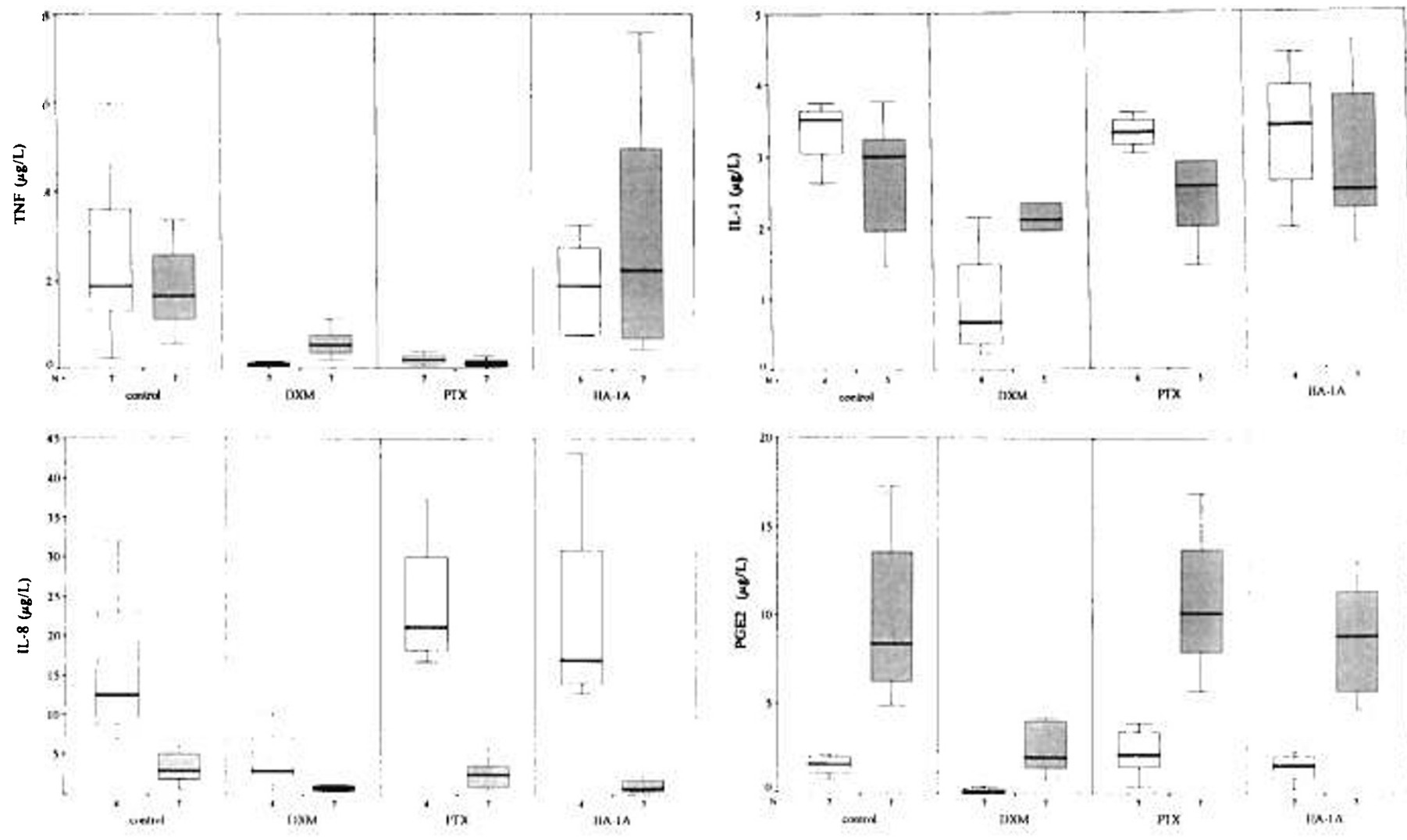

Fig. 2. The effects of DXM, PTX, and HA-1A on the release of TNF, IL-1 $\beta$, IL-8, and PGE 2 in whole blood ( $\square$ ) and by adherent monocytes (שR) stimulated with $H$. influenzae at $18 \mathrm{~h}$. Whole blood or adherent monocytes were incubated with $5 \times 10^{6}$ heat-killed $H$. influenzae alone or together with $0.5 \mathrm{mg} / \mathrm{L} \mathrm{DXM}, 100 \mathrm{mg} / \mathrm{L}$ PTX, or $40 \mathrm{mg} / \mathrm{L} \mathrm{HA}-1 \mathrm{~A}$ for $18 \mathrm{~h}$ at $37^{\circ} \mathrm{C}$ in $7.5 \% \mathrm{CO}_{2}$. The results are expressed as medians and $95 \%$ intervals of four to seven experiments. Boxes represent the interquartile range, median values are indicated by the horizontal bars within the boxes, and each set of horizontal lines defines $95 \%$ of the distribution.

the release of TNF (Fig. 2). The effect of PTX on the release of TNF was dose dependent, i.e. $10 \mathrm{mg} / \mathrm{L}$ caused a decrease in TNF release of $43 \pm 21 \%$ and $1 \mathrm{mg} / \mathrm{L}$ caused a decrease of $12 \pm$ $14 \%$. PTX had almost no effect on the release of the other mediators, i.e. IL-1 $\beta, \mathrm{IL}-8$, and $\mathrm{PGE}_{2}$ (Fig. 2), even at concentrations of PTX of $200 \mathrm{mg} / \mathrm{L}$ (data not shown). When adherent monocytes were incubated with heat-killed $H$. influenzae and $100 \mathrm{mg} / \mathrm{L}$ PTX, there was a significant $(p<0.01)$ reduction in the release of TNF of $92 \pm 6 \%$, whereas no significant $(p>0.1)$ effect on the other mediators was found, i.e. a $21 \pm 25 \%$ decrease in IL-8 release, a $12 \pm 14 \%$ decrease in IL- $1 \beta$ release, and a $6 \pm$ $10 \%$ decrease in $\mathrm{PGE}_{2}$ release (Fig. 2).

Effect of anti-endotoxin antibodies ( $H A-1 A$ ) on production of proinflammatory mediators. Whole blood incubated with heatkilled $H$. influenzae and $40 \mathrm{mg} / \mathrm{L} \mathrm{HA}-1 \mathrm{~A}$ reduced the release of TNF by $32 \pm 18 \%(p>0.1)$, IL- $1 \beta$ by $9 \pm 12 \%$, and PGE $_{2}$ by 8 $\pm 13 \%$; there was no effect on the release of IL-8 (Fig. 2). A higher dose $(400 \mathrm{mg} / \mathrm{L})$ of HA-1A inhibited the production of TNF slightly more (i.e. $47 \pm 19 \%$ ) but not significantly ( $p>$ 0.05 ), whereas the release of IL-1 $\beta$ decreased slightly but not significantly to $30 \pm 24 \%$.

Adherent monocytes incubated with heat-killed $H$. influenzae plus $40 \mathrm{mg} / \mathrm{L}$ HA-1 A exhibited a slight but significant reduction $(p<0.05)$ in the release of IL-8 $(46 \pm 42 \%)$ and an insignificant $(p>0.1)$ change in the release of TNF $(12 \pm 15 \%)$, IL- $1 \beta(4 \pm$ $8 \%$ ), and $\mathrm{PGE}_{2}(14 \pm 13 \%)$ (Fig. 2). HA-1A also did not affect the production of TNF and IL-1 in adherent monocytes stimulated with $10 \mu \mathrm{g} / \mathrm{L}$ endotoxin from Escherichia coli $(p>0.1)$ (data not shown). HA-1A bound to $H$. influenzae in a dosedependent fashion: binding of $1 \mu \mathrm{g}$ of HA-1A to $1 \times 10^{7}$ heatkilled $H$. influenzae $\left(\mathrm{OD}_{450}=0.769\right)$ was similar to the binding to $1 \mu \mathrm{g}$ of free LPS $\left(\mathrm{OD}_{450}=0.901\right)$ (Salmonella typhimurium,
Sigma, St. Louis, MO; K. M. C. Kwappenberg et al., unpublished results).

Release of cytokines by isolated monocytes, lymphocytes, and granulocytes. Incubation of elutriated monocytes incubated with heat-killed $H$. influenzae resulted in a high production of TNF $(3.7 \mu \mathrm{g} / \mathrm{L})$, which was similar to the TNF $(3.0 \mu \mathrm{g} / \mathrm{L})$ produced by a suspension of elutriated monocytes and elutriated lymphocytes stimulated by $H$. influenzae. Monocytes incubated in medium without $H$. influenzae did not produce detectable amounts of TNF and IL- $1 \beta$. Experiments with elutriated lymphocytes, granulocytes, or a combination of elutriated lymphocytes plus granulocytes, all incubated with $H$. influenzae, revealed no detectable production of TNF (data not shown). IL- $1 \beta$ release by elutriated lymphocytes $(22 \mathrm{ng} / \mathrm{L})$ or granulocytes $(21 \mathrm{ng} / \mathrm{L})$ stimulated by $H$. influenzae was negligible.

\section{DISCUSSION}

The main conclusion to be drawn from the present study is that DXM reduced the release of the major proinflammatory mediators, i.e. TNF, IL-1 $\beta$, IL-8, and $\mathrm{PGE}_{2}$, by $H$. influenzaestimulated monocytes, whereas PTX significantly reduced the release of TNF and HA-1A significantly reduced the release of IL-8. The results demonstrate that $H$. influenzae did not induce the release of TNF by isolated lymphocytes and granulocytes or a combination of lymphocytes and monocytes.

In experimental $H$. influenzae meningitis, DXM has a beneficial effect on the inflammatory response in the CNS (15). The mechanism of action of DXM in bacterial meningitis is unknown. It has been suggested that these effects are achieved through inhibition of inflammatory mediators. Our results demonstrate that DXM inhibits the production of a number of 
mediators in $H$. influenzae-stimulated whole blood. Similar results were obtained with adherent monocytes stimulated with $H$. influenzae, although the production of IL- $1 \beta$ was only slightly reduced by DXM. This is in agreement with clinical studies of infants and children with bacterial meningitis treated with anti-

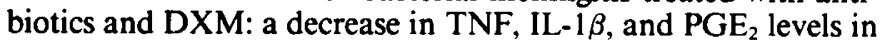
CSF and improvement of the outcome of sequelae were found $(6,10,11)$. The exact mechanisms by which DXM inhibits the production of proinflammatory mediators are not known. Various processes are influenced by $\mathrm{DXM}$, e.g. it inhibits the translation of TNF mRNA (16-18) and LPS-induced IL- $1 \beta$ formation (19).

The present results show that PTX is a rather specific inhibitor of TNF release by human leukocytes, inasmuch as the release of this cytokine, but not of IL-1 $\beta$, IL-8, and $\mathrm{PGE}_{2}$, was almost completely inhibited. In addition to the decrease in TNF release during bacterial meningitis, PTX also caused reduced leukocyte recruitment into CSF (12). In healthy volunteers, PTX prevented the elevation of plasma TNF levels after endotoxin infusion (13). These antiinflammatory effects might play an important role in the efficacy of PTX in bacterial meningitis in humans.

In the present study, the administration of the anti-endotoxin MAb HA- 1 A to limit cytokine release by $H$. influenzae-stimulated leukocytes was investigated. HA-1A binds to the lipid A part of LPS (20). In vitro studies showed that HA-1A did not inhibit the production of TNF, IL-1, and IL- 6 by LPS-stimulated monocytes (21) or improve the survival of mice challenged with Gram-negative bacteria or LPS (22). This is in agreement with our results; HA-1A decreased significantly only the production of IL-8 by adherent monocytes stimulated with $H$. influenzae, whereas no significant effect of HA-1A on the production of other inflammatory mediators, i.e. TNF, IL-1 $\beta$, and PGE , was $^{2}$ found. In whole blood stimulated with $H$. influenzae, HA-1A had no significant effect on the release of these mediators. In patients, HA-1A lowers serum TNF levels (23) and reduces mortality due to Gram-negative bacteremia with shock $(14,23$, 24). It has been reported that HA-1A mediates binding of LPS to complement receptor type 1 on erythrocytes, which in vivo might reduce the levels of circulating LPS, and thus inhibits TNF production (25). It might be that a similar mechanism occurs during an infection with $H$. influenzae.

This study shows that, of the three compounds investigated, DXM has the broadest effect. Routine use of DXM is still a subject of controversy among pediatricians, although it seems to decrease both neurologic and audiologic sequelae of $H$. influenzae meningitis.

\section{REFERENCES}

1. Schlech WF, Ward JI, Band JD, Hightower A, Fraser DW, Broome CV 1985 Bacterial meningitis in the United States, 1978 through 1981. JAMA 253:1749-1754

2. Saez-Llorens X, Ramilo O, Mustafa MM, Mertsola J, McCracken GH 1990 Molecular pathophysiology of bacterial meningitis: current concepts and therapeutic implications. J Pediatr 116:671-683

3. Tunkel AR, Wispelwey B, Scheld WM 1990 Bacterial meningitis: recent advances in pathophysiology and treatment. Ann Intern Med 112:610-623

4. McCracken GH, Mustafa MM, Ramilo O, Olsen KD, Risser RC 1989 Cerebrospinal fluid interleukin-1 beta and tumor necrosis factor concentration and outcome from neonatal gram-negative enteric bacillary meningitis. Pediatr J Infect Dis 8:155-159
5. Waage A, Halstenen A, Shalaby R, Brandtzaeg P, Kierulf P, Espevik T 1989 Local production of tumor necrosis factor $\alpha$, interleukin $i$, and interleukin 6 in meningococcal meningitis. J Exp Med 170:1859-1867

6. Mustafa MM, Lebel MH, Ramilo O 1989 Correlation of interleukin- $1 \beta$ and cachectin concentrations in cerebrospinal fluid and outcome from bacterial meningitis. J Pediatr 115:208-213

7. Baggiolini M, Sorg C 1992 Interleukin-8 (NAP-1) and related chemotactic cytokines. In: Baggiolini M, Sorg C (eds) Cytokines. Karger, Basel, pp 1-17

8. Tauber MG, Shibi AM, Hackbarth CJ, Sande MA 1987 Antibiotic therapy, endotoxin concentration in cerebral fluid, and brain edema in experimental Escherichia coli meningitis in rabbits. J Infect Dis 156:456-462

9. Arditi M, Ables L, Yogev R 1989 Cerebral fluid endotoxin levels in children with $H$. influenzae meningitis before and after administration of intravenous ceftriaxone. J Infect Dis 160:1005-1011

10. Lebel MH, Freij BJ, Syrogiannopoulos GA, Chrane DF, Hoyt MJ, Stewart SM, Kennard BD, Olsen KD, McCracken GH 1988 Dexamethasone therapy for bacterial meningitis. Results of two double-blind, placebo-controlled trials. N Engl J Med 319:964-971

11. Odio CM, Faingezicht I, Paris M, Nasser M, Baltodano A, Rogers J, SàezLlorens X, Olsen KD, McCracken GH 1991 The beneficial effects of early dexamethasone administration in infants and children with bacterial meningitis. N Engl J Med 324:1525-1531

12. Saezllorens X, Ramilo O, Mustafa MM 1990 Pentoxifylline modulates meningeal inflammation in experimental bacterial meningitis. Antimirob Agents Chemother 34:837-843

13. Zabel P, Schonharting MM, Wolter DT, Schade UF 1989 Oxpentifylline in endotoxaemia. Lancet 2:1474-1477

14. Ziegler EJ, Fisher CJ, Sprung CL, Straube RC 1991 Treatment of gramnegative bacteremia and septic shock with HA-1A human monoclonal antibody against endotoxin. $N$ Engl J Med 324:429-436

15. Mustafa MM, Ramilo O, Olsen KD, Franklin PS, Hansen EJ, Beutler B McCracken Jr GH 1989 Tumor necrosis factor in mediating experimental Haemophilus influenzae type b meningitis. J Clin Invest 84:1253-1259

16. Han J, Thompson P, Beutler B 1990 Dexamethasone and pentoxifylline inhibit endotoxin-induced cachectin/tumor necrosis factor synthesis at separate points in the signaling pathway. J Exp Med 172:391-394

17. Beutler B, Krochin N, Milsark IW, Luedke C, Cerami A 1986 Control of cachectin (tumor necrosis factor) synthesis: mechanisms of endotoxin resistance. Science 232:977-980

18. Strieter RM, Remick DG, Ward PA, Spengerl RN, Lynch JP, Larrick J, Kunkel SL 1988 Cellular and molecular regulation of tumor necrosis factoralpha production by pentoxifylline. Biochem Biophys Res Commun 155:1230-1236

19. Kern JA, Lamb RJ, Reed JC, Daniele RP, Nowell PC 1988 Dexamethasone inhibition of interleukin 1 beta production by human monocytes. J Clin Invest $81: 237-244$

20. Bogard WC, Siegel SA, Leone AO, Damiano E, Shealy DJ, Ely TM, Frederick B, Mascelli MA, Siegel RC, Machielse B, Naveh D, Kaplan PM, Daddona PE 1993 Human monoclonal antibody HA-1A binds to endotoxin via an epitope in the lipid A domain of lipopolysaccharide. J Immunol 150:44384449

21. Warren HS, Amato SF, Fitting C, Black KM, Loiselle PM, Pasternack MS, Cavaillon J 1993 Assessment of ability of murine and human anti-lipid monoclonal antibodies to bind and neutralize lipopolysaccharide. J Exp Med 177:89-97

22. Baumgartner JD, Heumann D, Gerain J, Weinbreck P, Grau GE, Glauser MP 1990 Association between protective efficacy of anti-lipopolysaccharide (LPS) antibodies and suppression of LPS-induced tumor necrosis factor $\alpha$ and interleukin-6. Comparison of $\mathrm{O}$ side chain-specific antibodies with core LPS antibodies. J Exp Med 171:889-896

23. Wortel $\mathrm{CH}$, von der Möhlen MAM, van Deventer SJH, Sprung CL, Jastremski M, Lubbers MJ, Smith CR, Allen IE, ten Cate JW 1992 Effectiveness of a human monoclonal anti-endotoxin antibody (HA-1A) in gram-negative sepsis: relationship to endotoxin and cytokine levels. J Infect Dis 166:1367sepsis:

24. van Dissel JT, van Furth R, Compier BA, Feuth HDM, Frolich M 1993 Survival in selected patients with gram-negative sepsis after adjunctive therapy with HA-1 A. [letter] Lancet 341:959-960

25. Tonoli M, Davies KA, Norsworthy PJ, Cohen J, Walport MJ 1993 The antilipid $A$ antibody HA-IA binds to rough Gram-negative bacteria fixes complement and facilitates binding to erythrocyte CRI (CD35). Clin Exp Immunol 92:232-238 